\title{
Some Investigations into the Dynamic Mass Transfer at the Slag-Metal Interface Using Sulfur: Concept of Interfacial Velocity
}

\author{
LUCKMAN MUHMOOD, NURNI N. VISWANATHAN, \\ and SESHADRI SEETHARAMAN
}

In the current work, dynamic studies of mass transfer of sulfur from the gas phase to the metal phase of pure iron through $\mathrm{CaO}-\mathrm{SiO}_{2}-\mathrm{Al}_{2} \mathrm{O}_{3}-\mathrm{FeO}$ quaternary slag were carried out. X-ray videos were taken that were later processed to identify the oscillation of the metal drop occurring during the mass transfer. It was observed that the metal drop had hybrid oscillations. Each of these oscillations could be identified as composed of a symmetric and an asymmetric element, which was attributed to the changes in the shape of the droplet. The latter (asymmetric part) could be identified by the deviation of the left and right contact angles from the stable configuration. The symmetric oscillations were traced to the surface movement of sulfur at the interface, which created an instantaneous area change at the slag-metal interface. This area change was due to the combined effect of Marangoni flow and interface dilatation. The velocity of sulfur at the interface was calculated from the area change and had a maximum order of magnitude as $10^{-4} \mathrm{~m} / \mathrm{s}$. It was also observed that the interfacial velocity increased with increase in temperature.

DOI: $10.1007 / \mathrm{s} 11663-011-9482-9$

(C) The Minerals, Metals \& Materials Society and ASM International 2011

\section{INTRODUCTION}

Numerous investigations have been carried out on surface phenomena, especially surface tension and surface energies pertaining to both slag and metal/alloy systems. $^{[1-5]}$ Interfacial phenomena studies mainly focusing on Marangoni forces and interfacial tensions have also been dealt with extensively. ${ }^{[6-10]}$ The potential drive for this extensive research is the importance of interfacial reactions in metallurgical process occurring during metal refining, degasification process, and slag entrapment. However, some issues with respect to the interfacial properties need to be addressed, viz. interfacial viscosities (both shear and dilatational). Currently, there has been no accurate measurement of these properties, although extensive studies have been carried out in colloidal systems. To the knowledge of the current authors, the only experiments to measure the surface shear viscosity were conducted by Popel et al..$^{[11]}$ and Hara et al. ${ }^{[12]}$ using an oscillating method and rotating plate viscometer, respectively. The authors

LUCKMAN MUHMOOD, Doctoral Student, formerly with the Department of Materials Science and Engineering, Division of Materials Process Science, Royal Institute of Technology, SE-10044 Stockholm, Sweden, is now with Aditya Birla Science and Technology Company Ltd., Navi Mumbai, India. Contact e-mail: luckman. muhmood@gmail.com NURNI N. VISWANATHAN, Associate Professor, is with the Department of Metallurgical Engineering \& Materials Science, Indian Institute of Technology, Bombay, Mumbai 400076, India. SESHADRI SEETHARAMAN, Professor, is with the Department of Materials Science and Engineering, Division of Materials Process Science, Royal Institute of Technology.

Manuscript submitted October 21, 2010.

Article published online March 11, 2011. obtained different viscosity values as a function of immersion depth. However, because the interface is of only few atomic layers thick, the values obtained would strictly not represent the surface property but would be closer to the bulk values. To study these properties, it is highly essential to focus on dynamic interfacial phenomena as these properties involve changes in flow rates and interfacial areas.

The current work takes inspiration from the earlier works wherein it was reported that during intense mass transfer between two phases, low apparent interfacial tension resulted. ${ }^{[13-15]}$ In these works, iron containing higher oxygen content was introduced into a slag-iron system that was maintained already at equilibrium at a lower oxygen level. A sharp decrease in the interfacial tension was observed caused by the surface-active oxygen and, consequently, was dependent on the oxygen content in the liquid iron. This difference later decreased but was stabilized at a lower interfacial tension. However, because the mass transfer involved a solid-solid interface, the question arises regarding the precision of the values obtained.

Another work along around which the concept of the present article revolves is that of Jakobsson et al. ${ }^{[16]} \mathrm{In}$ this work, mass transfer of sulfur from gaseous phase to a metal drop through an alumina-saturated $\mathrm{CaO}-\mathrm{SiO}_{2}-$ $\mathrm{Al}_{2} \mathrm{O}_{3}-\mathrm{FeO}$ slag to the metal sample (sulfurization process) was envisaged. In this work, the source of sulfur would be a gas. In this way, the errors involved by mixing and other similar phenomena were reduced. It was observed using an X-ray source that, under dynamic conditions, the drop shape changed because of the sulfur movement along the interface and into the bulk of the drop. The property "interfacial velocity" using sulfur 
was estimated by these authors semiempirically. The experiments needed precision and the data analysis as well as modeling required refinement. The current work is aimed at analyzing the interfacial phenomena more critically during the sulfurization of iron. This would involve an in-detail study of the nature of the oscillations occurring because of the movement of sulfur at the slag-metal interface and the calculation of the interfacial velocity. A rigorous formulation of the concept of interfacial velocity needed to be formulated as a part of the current work.

\section{THEORY}

In the current work, the effect of a surface-active element like sulfur at the iron-slag interface is considered as a means to measure interfacial velocity. Sulfur, delivered by a gas mixture of Ar-CO-SO $\mathrm{SO}_{2}$ at the surface of a slag, would pass through the slag composed of $\mathrm{CaO}-\mathrm{SiO}_{2}-\mathrm{Al}_{2} \mathrm{O}_{3}-\mathrm{FeO}$ and reach to the molten metal drop. As oxygen present in the gas mixture is also a potential competitor for sulfur, the chemical potential of oxygen was maintained the same in gas, metal, and slag phases. This would ensure that sulfur would be the only species entering the metal phase via the slag-metal.

\section{A. Concept of Interfacial Velocity}

An attempt to quantify the interfacial velocity, based on experiments examining the interfacial phenomena, was made (as mentioned earlier) first in a research work conducted at the Division of Materials Process Science, Royal Institute of Technology. ${ }^{[16]}$ During the sulfurization process of pure iron using a gas mixture of Ar-CO- $-\mathrm{CO}_{2}-\mathrm{SO}_{2}$, it was found that the drop oscillated after roughly one hour from the commencement of the gas introduction into the furnace. The following explanation was given as the cause for these oscillations, which is illustrated in Figure 1. Sulfur was transferred from the gas phase to the metal phase through an

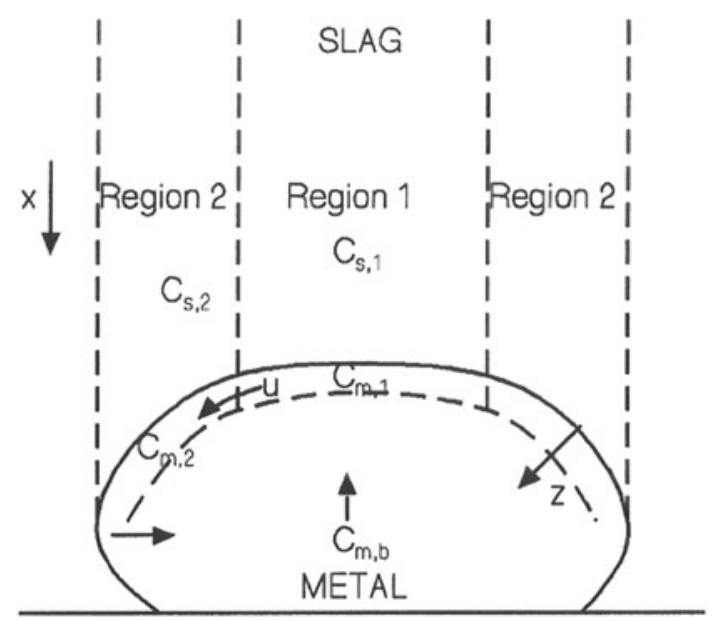

Fig. 1-Droplet oscillation caused by sulfur movement along the surface and bulk of the metal droplet. alumina-saturated quaternary slag consisting of $\mathrm{CaO}$ $\mathrm{SiO}_{2}-\mathrm{Al}_{2} \mathrm{O}_{3}-\mathrm{FeO}$. As the slag and the metal were maintained under equilibrium condition at $1886 \mathrm{~K}$ $\left(1612{ }^{\circ} \mathrm{C}\right)$ throughout the experiment in the constant temperature zone of the furnace $\left( \pm 2 \mathrm{~K} / \pm 2{ }^{\circ} \mathrm{C}\right)$, the thermal convection in the slag and metal phases were assumed to be negligible. Hence, diffusion through slag medium was the only possible mechanism for sulfur to reach the slag-metal interface. It was also assumed that, because the electrochemical reactions taking place at the slag-metal interface were instantaneous, the impact of these reactions could be neglected. Because of the contour of the sessile drop, the slag above it was divided approximately into two regions as shown in Figure 1. Region 1 was the shortest path to the metal drop; hence, the sulfur would reach the slag-metal interface at this region initially. This would result in an interfacial tension gradient along the slag-metal interface, which would induce Marangoni flow leading to the flattening of the drop. The flow of sulfur along the contour of the metal drop, together with the diffusion of sulfur into the bulk, would result in the depletion of sulfur from the top of the metal drop, which in turn would regain its shape temporarily. A mathematical formulation using mass-balance equations was made through which the order of magnitude of the interfacial velocity was determined as $10^{-6} \mathrm{~m} \mathrm{~s}^{-1}$ semiempirically.

The drawback of this research work was that reproducibility was not ascertained and the temperature dependence was not measured. Hence, the current authors have designed a new set of experiments by which the interfacial velocity could be determined experimentally. In the current work, Ar-CO- $\mathrm{SO}_{2}$ was used to maintain the $p_{O_{2}}$ and $p_{s_{2}}$ pressures at $10^{-4}$ and $10^{3} \mathrm{~Pa}$, respectively. The oscillations observed in accordance with the mechanism explained previously would lead to a change in the contour of the drop. This was attributed to the dilatational effect caused by the Marangoni flow. The interfacial area in this case would change; hence, it was necessary to compute this change in interface area to measure the velocity resulting from the concentration difference of sulfur at the interface. Because the cause and effect of the interfacial area change was from the same source, the area change during an oscillation would enable the determination of the interfacial velocity of sulfur.

\section{B. Gas-Slag-Metal Equilibrium}

Equilibrium conditions for the gas-slag-metal system were maintained at $1823 \mathrm{~K}\left(1550{ }^{\circ} \mathrm{C}\right)$ and 1 bar pressure. The gas-slag-metal equilibrium is represented in Figure 2.

The gas mixture entering the furnace space, especially the crucible, undergoes an instantaneous redox reaction because of the high temperature prevailing, and an equilibrium partial pressure of $\mathrm{S}_{2}$ gas is maintained.

The sulfur gas reaching the gas-slag interface then undergoes an electrochemical reaction by which it forms $\mathrm{S}^{2-}$ ions and positive charges.

$$
\mathrm{S}_{2}+4 \mathrm{e}^{-} \rightarrow 2\left\{\mathrm{~S}^{2-}\right\}
$$




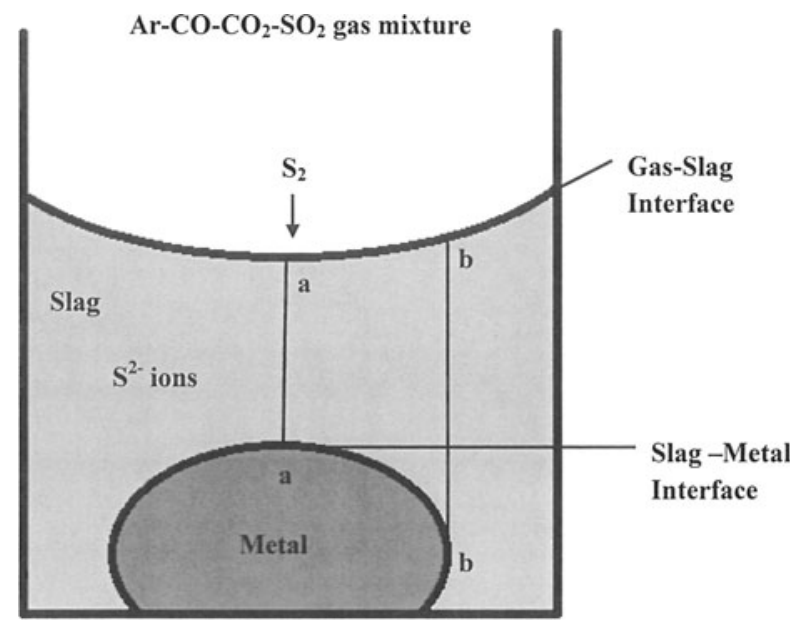

Fig. 2- Gas-slag-metal equilibrium with interfaces.

These sulfur ions then move down through the slag phase because of the chemical potential difference and migrate to the slag-metal interface where they again undergo an electrochemical reaction in which the sulfur ions are converted to atoms in the metal phase.

$$
\left\{\mathrm{S}^{2-}\right\} \leftrightarrow \underline{\mathrm{S}}+2 \mathrm{e}^{-}
$$

Because sulfur is a surface-active element, most of the atoms will move along the surface of the metal drop, whereas some of them would enter the metal bulk phase to a particular depth. Assuming that the electrochemical reactions taking place at the interfaces are extremely fast $^{[17]}$ and the effect of the convection flow on mass transfer is negligible as the temperature gradient is insignificant, the surface velocity of sulfur at the slagmetal interface could be estimated from the oscillations produced because of the superficial movement of the sulfur ions.

As shown in Figure 2, the slag-gas interface has a concave interface contour, whereas the contour of the slag-metal interface is convex. Hence, the distance between the corresponding points in the slag-gas interface and that of the slag metal interface is actually building up as one goes from point " $\mathrm{a}$ " toward point "b," the outer edge of the drop. It is possible to estimate approximately the time taken for sulfur to reach various parts on the contour, viz. point "a" to point "b." Considering adjacent points along the contour to be of the order of $0.01 \mathrm{~mm}$ and knowing the order of diffusivity of sulfur in slag to be $10^{-6} \mathrm{~cm}^{2} \mathrm{~s}^{-1},{ }^{[18]}$ it can be established easily that the difference in time for sulfur to reach these points would be of the order of 0.1 seconds. Because the order of magnitude of sulfur diffusion in metal phase is two orders of magnitude higher than that in the slag phase and considering that the surface diffusion of sulfur in the metal phase is predominant in comparison with the bulk diffusion, we can conclude that this time difference ( 0.1 seconds) is enough for the first atom to move around the curved interface, giving rise to the oscillation movement. Hence, the video recording time would be large enough to capture this oscillation.

\section{At the Interface}

As shown previously, interfacial velocity is the combined effect of the Marangoni force (force caused by an interfacial tension difference) and the forces that cause interface dilatation. Thus, it would be of great interest to study the force balances at the interface during such mass transfer process. The basic assumptions for the current approach are as follows:

(a) Constant partial pressures of oxygen and sulfur are maintained in the gas phase and $\mu_{\mathrm{o}}^{\text {gas }} \ll \mu_{\mathrm{s}}^{\text {gas }}$ which would establish that sulfur enters the metal phase predominantly.

(b) The interfacial reactions are electrochemical in nature and take place fast in comparison with the diffusion process. ${ }^{17]}$

(c) The diffusion of sulfur into the bulk of the metal phase is much slower in comparison with the surface diffusion because of the availability of "dangling" metallic bonds at the interface.

The sulfur reaching the interface will be experiencing the following forces:

(a) An upward force because of the pull toward the slag phase. This upward pull would depend mainly on the sulfide capacity of the slag.

(b) A downward pull toward the metal phase mainly because of the free metal bonds at the surface and the gravitational force, the latter in this case being negligible.

(c) Marangoni force caused by the surface/interfacial tension gradient on the surface of the metal drop at the slag-metal interface. The force would act along the interface in a direction toward the lower surface concentration of the surfactant.

(d) Dilatational force that causes an increase in the surface area because of the varying interfacial tension force.

(e) Brownian motion of the sulfur atoms that would depend on the temperature of the system.

\section{Dimension Analysis and Dependence on Other Properties}

To find a suitable equation for the interfacial velocity, a dimension analysis approach was used. In this approach, the velocity is written as a function of the possible terms that would have a direct effect on it.

Interfacial tension, $\sigma$ : This variable has a direct effect on the interfacial velocity as it represents the degree of bonding at the surface. The greater the bonding, the lower will be the interfacial velocity. The surface tension can be measured from the contour of the sessile drop using the Adams-Bashforth equation. ${ }^{[19]}$

Interfacial shear viscosity, ${ }^{[2]} \mu_{\mathrm{S}}$ : This variable has a limited impact on the interfacial velocity as it represents the resistance offered on the interfacial layer by the immediate layer beneath. It also depends on the 
interfacial tension, in the absence of an external shear force. It could be represented by the equation

$$
\frac{\Delta \sigma}{\Delta R}=\mu_{\mathrm{S}} \frac{\Delta v}{X}
$$

Interfacial dilational viscosity, ${ }^{[21]} K_{\mathrm{d}}$ : It represents the increase in area caused by the relative movement of the atom layers. It is represented as

$$
\Delta \sigma=K_{\mathrm{d}} \frac{1}{A_{t}} \frac{\Delta A}{\Delta t}
$$

Surface diffusion of sulfur in slag, $D_{\mathrm{S}}$ : This is related to the interfacial velocity as it directly represents the movement of the sulfur atoms due to concentration gradient at the interface. It is generally estimated by suitable chemical or radioactive experiments.

Writing the surface velocity as a function of the above variables

$$
v=f\left(\sigma, D_{\mathrm{S}}, K_{\mathrm{d}}, \mu_{\mathrm{S}}\right)
$$

Using the dimensional analysis approach

$$
v=C \sigma^{a} D_{\mathrm{S}}^{b} K_{\mathrm{d}}^{c} \mu_{\mathrm{S}}^{d}
$$

Where $C, a, b, c$ and $d$ are constants. By solving Eq. [2], we get

$$
v=C \sqrt{\frac{\sigma D_{\mathrm{S}}}{K_{\mathrm{d}}}}\left[\sqrt{\frac{D_{\mathrm{S}}}{K_{\mathrm{d}} \sigma}} \mu_{\mathrm{S}}\right]^{d}
$$

The term within the square brackets of Eq. [5] is dimensionless. Because $C$ and $d$ are constants that need to be calculated experimentally, an alternate way to solve Eq. [5] would be to collect the constants together to write the previous equation as

$$
v=\sqrt{\frac{\sigma D_{\mathrm{S}}}{K_{\mathrm{d}}}} \phi\left[\sqrt{\frac{D_{\mathrm{S}}}{K_{\mathrm{d}} \sigma}} \mu_{\mathrm{S}}\right]
$$

Where $\phi$ is a function given as

$$
\phi\left[\sqrt{\frac{D_{\mathrm{S}}}{K_{\mathrm{d}} \sigma}} \mu_{\mathrm{S}}\right]=C\left[\sqrt{\frac{D_{\mathrm{S}}}{K_{\mathrm{d}} \sigma}} \mu_{\mathrm{S}}\right]^{d}
$$

It can be estimated by plotting the graph taking $v \sqrt{\frac{K_{\mathrm{d}}}{\sigma D_{\mathrm{S}}}}$ on the $y$-axis and $\mu_{\mathrm{S}} \sqrt{\frac{D_{\mathrm{S}}}{K_{\mathrm{d}} \sigma}}$ on the $x$-axis. A smooth curve could be fitted to find the nature of the unknown function.

During dynamic studies, it is not reliable to calculate the interfacial tension because nonequilibrium conditions prevail. However, the interfacial tension values can be substituted with contact angle as

$$
\sigma=k^{\prime \prime} / \cos \theta
$$

Interfacial velocity can be measured for surface-active elements like oxygen, sulfur, and phosphorous, all of which are important in metallurgy. Depending on the size of these atoms and the affinity of the free iron bonds on the metal surface to attract them, the interfacial velocities may vary. A higher velocity would indicate an easy removal from the surface during refining. Furthermore, because there is a dilatational term involved, the interfacial area change would play a crucial role in the refining process as well.

\section{EXPERIMENTAL}

\section{A. Materials}

In the current work, iron (99.995 pct pure) was selected as the metal phase and was kept immersed in a $\mathrm{CaO}-\mathrm{SiO}_{2}-\mathrm{Al}_{2} \mathrm{O}_{3}-\mathrm{FeO}$ molten slag of well-defined composition. Dense alumina of 99.7 pct purity was selected as the crucible material. The slag was chosen in the alumina-saturated region to avoid any reaction with the crucible material. The composition of the slag and its purity are shown in Table $\mathrm{I}$. FeO was prepared from iron powder and $\mathrm{Fe}_{2} \mathrm{O}_{3}$. The two components were mixed in a suitable ratio so that the resulting $\mathrm{FeO}$ could have a composition close to the $\mathrm{FeO} / \mathrm{Fe}$ phase boundary at the experimental temperature. ${ }^{[22]}$ The mixture was then heated in a closed iron crucible in argon atmosphere at $1273 \mathrm{~K}\left(1000{ }^{\circ} \mathrm{C}\right)$ for 24 hours and later quenched. An X-ray diffraction analysis of $\mathrm{FeO}$ thus produced showed that the sample corresponded to wüstite and that it contained no free iron or magnetite. From the diffraction pattern, the lattice parameter of the $\mathrm{FeO}$ produced was computed to be $4.30 \AA$, which is in agreement with the literature value of $4.3088 \AA$ given by the X-ray database.

The gas mixture used during the experiment was composed of Ar-CO-SO $\mathrm{S}_{2}$. The gas mixture was introduced at a predetermined flow rate so that the $p_{\mathrm{O}_{2}}$ and $p_{\mathrm{S}_{2}}$ partial pressures were $10^{-4}$ and $10^{3} \mathrm{~Pa}$, respectively; these values were verified using Thermo-Calc (Sweden). ${ }^{[23]}$

\section{B. Apparatus}

The apparatus used for the sessile-drop measurements consisted of an X-ray unit equipped with an image analyzer and a graphite resistance furnace. A schematic diagram of experimental apparatus is shown in Figure 3. This combination of X-ray unit and the high-temperature furnace was employed to observe the metal drop immersed in the slag to monitor the interfacial phenomena and the shape of sessile drop. The X-ray unit used was a PHILIPS BV-26 imaging system with an X-ray source ranging from 40 to $105 \mathrm{kV}$. The imaging system consists of a charge-coupled device (CCD) camera with digital noise reduction. The recording system consists of a Dell PC equipped with an image acquisition card to

Table I. Details of the Raw Materials Used for Slag Preparation

\begin{tabular}{lcc}
\hline Material & Purity (Metal Basis) & Composition (wt pct) \\
\hline $\mathrm{CaO}$ & 99.95 & 22.9 \\
$\mathrm{Al}_{2} \mathrm{O}_{3}$ & 99.97 & 54.1 \\
$\mathrm{SiO}_{2}$ & 99.8 & 18.0 \\
$\mathrm{FeO}$ & - & 5.0 \\
\hline
\end{tabular}




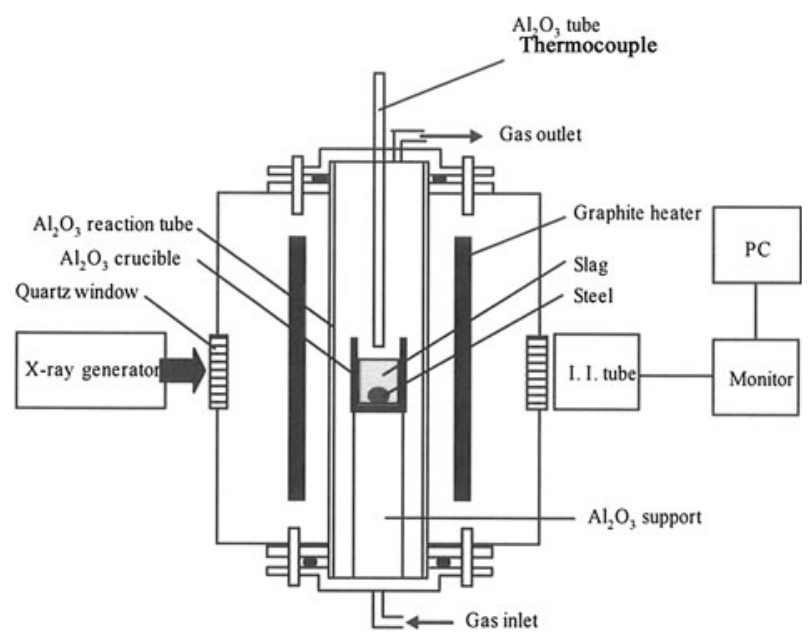

Fig. 3-A schematic illustration of apparatus.

monitor and record the $\mathrm{X}$-ray images at a maximum rate of 25 frames per second.

The furnace used in the experiments was the model 1000-3500-FP20 acquired from Thermal Technology Inc. (Santa Rosa, CA). It is equipped with graphite heating elements (effect $=20 \mathrm{kVA})$. The furnace temperature was controlled by a type B thermocouple.

Quartz windows of $40 \mathrm{~mm}$ in diameter were provided on the opposite sides of the furnace for the $\mathrm{X}$-ray source and detector. A recrystallized $\mathrm{Al}_{2} \mathrm{O}_{3}$ reaction tube, with an inner diameter of $60 \mathrm{~mm}$, was positioned vertically in the furnace. Radiation shields were placed inside the reaction tube on both sides of the even temperature zone to extend the same. Experiments for temperature calibration showed that the temperature was constant within $\pm 2 \mathrm{~K}\left( \pm 2{ }^{\circ} \mathrm{C}\right)$ over a length of at least $50 \mathrm{~mm}$ under the conditions of the current experiment.

An appropriate gas-cleaning train was incorporated in the system to ensure that the impurity levels in the argon gas used were low. Argon gas was dried by silica gel and $\mathrm{Mg}\left(\mathrm{ClO}_{4}\right)_{2}$. Ascarite was used to remove carbon dioxide. Traces of oxygen were removed by passing the gas first through copper turnings at $903 \mathrm{~K}\left(630^{\circ} \mathrm{C}\right)$ and then through magnesium chips at $703 \mathrm{~K}\left(430{ }^{\circ} \mathrm{C}\right)$. The entire system was capable of operating under vacuum as well as under argon or other gas mixtures. The flow rate of the gas was controlled and monitored using BRONKHORST HI-TEC mass flow meters/controllers connected to a channel digital readout and control system FLOW-BUS. The gas coming out from the furnace was led through an oxygen probe situated in a separate furnace outside the main reaction furnace. This oxygen probe was equipped with calcia-stabilized zirconia galvanic cell maintained at $973 \mathrm{~K}\left(700{ }^{\circ} \mathrm{C}\right)$ with air as the reference electrode monitoring the oxygen partial pressure of the outgoing gas. According to the literature, ${ }^{[24]}$ gas mixtures do not attain equilibrium at temperatures below $1273 \mathrm{~K}$ $\left(1000^{\circ} \mathrm{C}\right)$. In the current experimental setup, the oxygen sensor was used mainly to monitor the stability of the $p_{\mathrm{O}_{2}}$ of the gas mixture entering the furnace. The oxygen sensor was initially calibrated with $\mathrm{O}_{2}$ gas prior to the experiment.

\section{Methodology}

Pure iron metal of $2.11 \mathrm{~g}$ and $22 \mathrm{~g}$ slag were taken in the alumina crucible and were heated up to $1823 \mathrm{~K}$ $\left(1550^{\circ} \mathrm{C}\right)$ in the X-ray apparatus. The sample was held at constant temperature for approximately 110 minutes in an atmosphere of $\mathrm{Ar}-\mathrm{CO}-\mathrm{CO}_{2}$. The ratio of gases was chosen so that the $\mathrm{Fe} / \mathrm{FeO}$ equilibrium was maintained at high temperatures. After holding the sample at the temperature of interest, a gas mixture of $\mathrm{Ar}_{-} \mathrm{SO}_{2}-\mathrm{CO}$ was passed at predetermined flow rates. The flow rates of the gases ensured no change in the oxygen partial pressure in the gas phase and the partial pressure of sulfur in the system was maintained at $10^{3} \mathrm{~Pa}$. X-ray photographs as well as videos were taken to conduct the dynamic as well as static measurements. Suitable amounts of the metal and the slag were chosen so that a slag thickness of roughly $1-1.5 \mathrm{~mm}$ was maintained above the metal, thus ensuring least recording time for the X-ray machine to capture the sulfur entry.

For calculating the time for sulfur diffusion to occur through the slag and reach the slag-metal interface, a mathematical model was developed for 1-dimensional diffusion. ${ }^{[18]}$ This model was validated later by experiments. ${ }^{[25]}$ The inputs to the model were the density of the slag, density of the metal, sulfide capacity of the slag, solubility sulfur in liquid iron, and diffusivity of sulfur in the slag and liquid iron. The density of the slag was measured using the sessile drop technique, the density of the metal, and the diffusivities of sulfur through liquid iron and slag was taken from data available in the literature. ${ }^{[26,27]}$ The sulfide capacity was calculated from Thermoslag. ${ }^{[28]}$ A program was written in MATLAB ${ }^{[29]}$ for estimating the time taken for sulfur to reach the slag-metal interface. The estimated time for sulfur to reach the slag-metal interface was calculated as 10 minutes. Accordingly, videos were taken intermittently for the first 40 minutes after the sulfur source injection into the system. Because of the limitations in the video recording time by the X-ray apparatus, it was not possible to record the oscillations for more than 32 minutes.

\section{Realization from Experiments}

As discussed previously, the movement of sulfur along the interface of the sessile drop could be traced by the fluctuations in the surface of the drop. The same was observed in previous experiments as well. ${ }^{[16]}$ To estimate the surface velocity resulting from the sulfur concentration variation at the interface, the oscillation of the drop should be taken into consideration. The oscillations of the drop would lead to a change in the surface area of the metal drop. This change in surface area could be equated with a circle of a defined radius. Hence, the change in the drop shape because of oscillation would lead to the change in surface area and, consequently, a change in the radius of the circle. As both the cause and effect of the change in drop surface area could be attributed to the sulfur concentration change along the interface, one cycle consisting of a dip and rebound of the interface area is needed to be considered at a time. 
If $R_{t}$ is the radius of the equivalent circle of the drop with initial surface area $A_{t}$ at any time $t$ and $R_{t+\Delta t}$ is the radius of the circle for drop with surface area $\mathrm{A}_{t+\Delta t}$ at the next instant $t+\Delta t$, the relationship between the change in interfacial velocity of sulfur at the interface and the rate of change of the radius causing the oscillation of the drop is given by the equation

$$
v_{\text {instantaneous }}=\frac{R_{t+\Delta t}-R_{t}}{\Delta t}
$$

\section{RESULTS AND DISCUSSION}

\section{A. Calibration}

Prior to the experiments, a calibration of the X-ray apparatus was carried out by investigating the surface tension of silver. Approximately $1.508 \mathrm{~g}$ silver was reduced initially in a thermogravimetric unit in hydrogen atmosphere and slowly cooled ensuring that there was no residual hydrogen. The surface tension of this silver specimen was measured in the current X-ray sessile drop unit. The surface tension of silver was measured at $1273 \mathrm{~K}, 1303 \mathrm{~K}, 1335 \mathrm{~K}$, and $1378 \mathrm{~K}$ $\left(1000{ }^{\circ} \mathrm{C}, 1030{ }^{\circ} \mathrm{C}, 1062^{\circ} \mathrm{C}\right.$, and $\left.1105^{\circ} \mathrm{C}\right)$. A relationship between the surface tension and temperature was

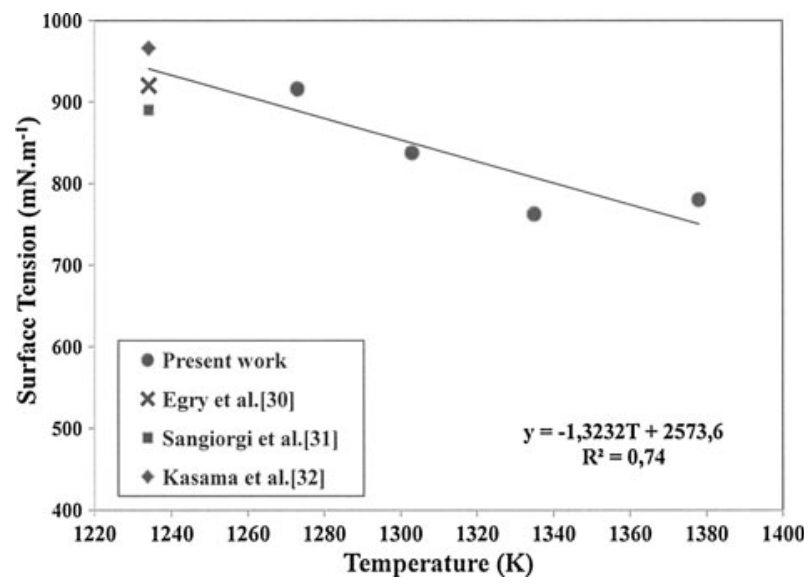

Fig. 4 - Surface tension values of pure silver. derived, and this relation was used to find the surface tension at the melting point. The surface tension values are shown in Figure 4.

Extrapolating the surface tension value for silver to its melting point, the value obtained was estimated to be $939 \mathrm{mN} / \mathrm{m}$, which is in good agreement with the values of other researchers as shown in Figure 4.

The furnace had also been calibrated earlier with other metals like copper, nickel and iron ${ }^{[8]}$

$$
\begin{aligned}
& \mathrm{Cu}: \sigma\left(\mathrm{Nm}^{-1}\right)=1.322-0.3286 \times 10^{-3}(T-1356 \mathrm{~K}) \\
& \mathrm{Ni}: \sigma\left(\mathrm{Nm}^{-1}\right)=1.810-0.3286 \times 10^{-3}(T-1728 \mathrm{~K})
\end{aligned}
$$

The temperature calibration of the furnace was done by using pure iron sample. The iron sample of mass $2 \mathrm{~g}$ and purity 99.995 pct was loaded in an alumina crucible. The melting point of iron was measured, and using this temperature, the furnace was calibrated. The uniform temperature zone was measured using a B-type thermocouple kept close to the molten metal and slowly lifting it to a predetermined height; hence, the temperature variation along the crucible height could also be determined. The crucible was observed to be in the uniform temperature zone.

\section{B. Slag Density Estimation}

The estimation of interfacial tension between slag and metal requires the knowledge of the respective densities. As the density of pure iron metal is well known, only the density of the slag used was to be precisely determined to calculate the interfacial tension. Approximately $0.41 \mathrm{~g}$ slag was made to a pellet and then mounted on a Pt-30 pct $\mathrm{Rh}$ foil, which was finally placed in the furnace. The volume variation with respect to temperature was studied with the help of X-ray radiography. This change in volume was used later to find the density of the slag. The value thus obtained was compared with the model developed by the division. The model was validated previously by the current authors by conducting density measurements using Archimedes principle. ${ }^{[33]}$ Figure 5 shows the various stages of the slag pellet with temperature increase. The density and surface tension values of the slag were calculated at
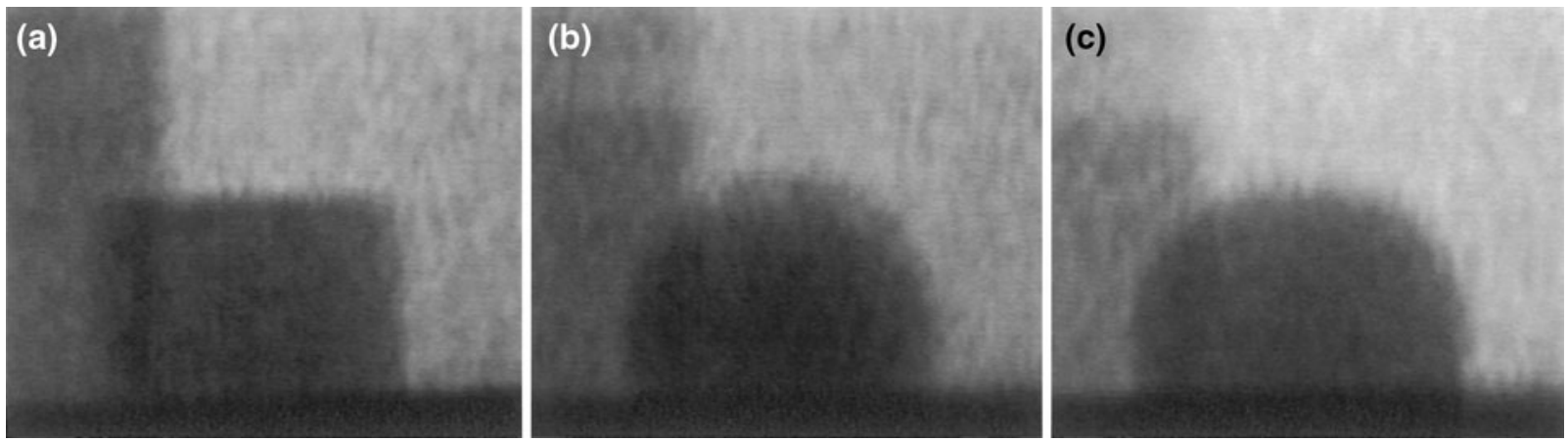

Fig. 5-Density calculation of 22.9 pct $\mathrm{CaO}-18$ pct $\mathrm{SiO}_{2}-54.1$ pct $\mathrm{Al}_{2} \mathrm{O}_{3}-5$ pet $\mathrm{FeO}$ quaternary slag. (a) pellet at room temperature, (b) at $1823 \mathrm{~K}\left(1550{ }^{\circ} \mathrm{C}\right)$ after $105 \mathrm{~min}$ holding, and $(c)$ at $1873 \mathrm{~K}\left(1600{ }^{\circ} \mathrm{C}\right)$ after $100 \mathrm{~min}$ holding. 
$1823 \mathrm{~K}$ and $1873 \mathrm{~K}\left(1550{ }^{\circ} \mathrm{C}\right.$ and $\left.1600^{\circ} \mathrm{C}\right)$, respectively. Table II shows the variation of the density and surface tension with respect to temperature increase. The experimental density values were also compared with those obtained using the model developed by Persson et al. ${ }^{[34]}$ corresponding to similar temperatures.

\section{Work of Adhesion and Interaction Coefficient}

The work of adhesion ${ }^{[35]}$ is an indication of the work required to be done to separate the metal and slag phases. This represents (at least partially) the force that would oppose the movement of sulfur at the interface. It also represents the degree of interaction between the metal and slag phases. When the work of adhesion increases, the interfacial velocity of sulfur would decrease. It is defined as

$$
W_{\mathrm{ad}}=\sigma_{\mathrm{m}}+\sigma_{\mathrm{s}}-\sigma_{\mathrm{ms}}
$$

The interaction coefficient $(\phi)$ from the Girifalco and Good equation ${ }^{[36]}$ is a measure of the interaction between two condensed phases (here: slag and metal) and is defined as the ratio of the work of adhesion between the two phases and the square root of the work of cohesion of each individual phase as follows

$$
\phi=\frac{W_{\mathrm{ad}}}{\left(W_{\mathrm{co}}^{\mathrm{m}} W_{\mathrm{co}}^{\mathrm{s}}\right)^{\frac{1}{2}}}=\frac{\sigma_{\mathrm{m}}+\sigma_{\mathrm{s}}-\sigma_{\mathrm{ms}}}{2 \sqrt{\left(\sigma_{\mathrm{m}} \sigma_{\mathrm{s}}\right)}}
$$

Table II. Surface Tension and Density Values of 22.9 pct CaO-18 pet $\mathrm{SiO}_{2}-54.1$ pet $\mathrm{Al}_{2} \mathrm{O}_{3}-5$ pet $\mathrm{FeO}$ Quaternary Slag

\begin{tabular}{lccc}
\hline $\begin{array}{l}\text { Temperature, } \\
\mathrm{K}\left({ }^{\circ} \mathrm{C}\right)\end{array}$ & $\begin{array}{c}\text { Surface } \\
\text { Tension } \\
\left(\mathrm{mN} \mathrm{m}^{-1}\right)\end{array}$ & $\begin{array}{c}\text { Density } \\
\left(\mathrm{g} \mathrm{cm}^{-3}\right)\end{array}$ & $\begin{array}{c}\text { Density } \\
(\text { Persson } \text { et al. } \\
\left(\mathrm{g} \mathrm{cm}^{-3}\right)\end{array}$ \\
\hline $1823(1550)$ & 325.4 & 2.74 & 2.97 \\
$1873(1600)$ & 292.3 & 2.69 & 2.94 \\
\hline
\end{tabular}

For pure iron the surface tension is given as ${ }^{[37]}$

$$
\sigma_{\mathrm{m}}=1872-0.49\left(T-T_{M}\right)
$$

For the current slag-metal system, the work of adhesion is computed and shown in Table III. The table shows that the interaction between slag and metal phases increases with increase in temperature as the interaction being repulsive, there would be a lower energy required for the sulfur atoms to move along the interface at $1873 \mathrm{~K}\left(1600{ }^{\circ} \mathrm{C}\right)$. The same is observed by a decrease in the work of adhesion with respect to temperature increase.

\section{Interfacial Oscillations and Velocity}

As we have discussed previously, the movement of sulfur along the interface of the sessile drop could be traced by the fluctuations in the surface of the drop. These oscillations were absent before the introduction of sulfur into the system. The same was observed in previous experiments by Jakobsson et al. ${ }^{[16]}$ To estimate the surface velocity of sulfur at the interface, the oscillations of the drop were taken into consideration. Figure 6 shows the sessile drop contour at different time intervals. As observed from the figure, it is difficult to identify the change in the height and width of the drop manually. However, a significant change in contact angle can be visualized. The dynamic oscillations were captured by the X-ray CCD camera run on a video mode. The video files taken were then segmented into picture frames at the rate of 25 frames per second using VirtualDub ver.1.9.9.0 software. This would help in identifying individual oscillations and could keep record of the time between depression and expansion (dip and rebound) of the drop. As cropping the picture frames would introduce human errors, it was decided to use a MATLAB ${ }^{[29]}$ program to crop the frames with the same threshold value for each frame. Additionally, a program

Table III. Work of Adhesion and Interaction Coefficient Variation with Temperature

\begin{tabular}{lccccc}
\hline Temperature, $\mathrm{K}\left({ }^{\circ} \mathrm{C}\right)$ & $\sigma_{\mathrm{m}}\left(\mathrm{mN} \mathrm{m}^{-1}\right)$ & $\sigma_{\mathrm{s}}\left(\mathrm{mN} \mathrm{m}^{-1}\right)$ & $\sigma_{\mathrm{ms}}\left(\mathrm{mN} \mathrm{m}^{-1}\right)$ & $\mathrm{W}_{\mathrm{ad}}\left(\mathrm{mN} \mathrm{m}^{-1}\right)$ & Interaction Coefficient $\phi$ \\
\hline $1823(1550)$ & 1865.1 & 325.4 & 1417.8 & 772.7 & 0.496 \\
$1873(1600)$ & 1840.6 & 292.3 & 1375.9 & 757 & 0.516 \\
\hline
\end{tabular}
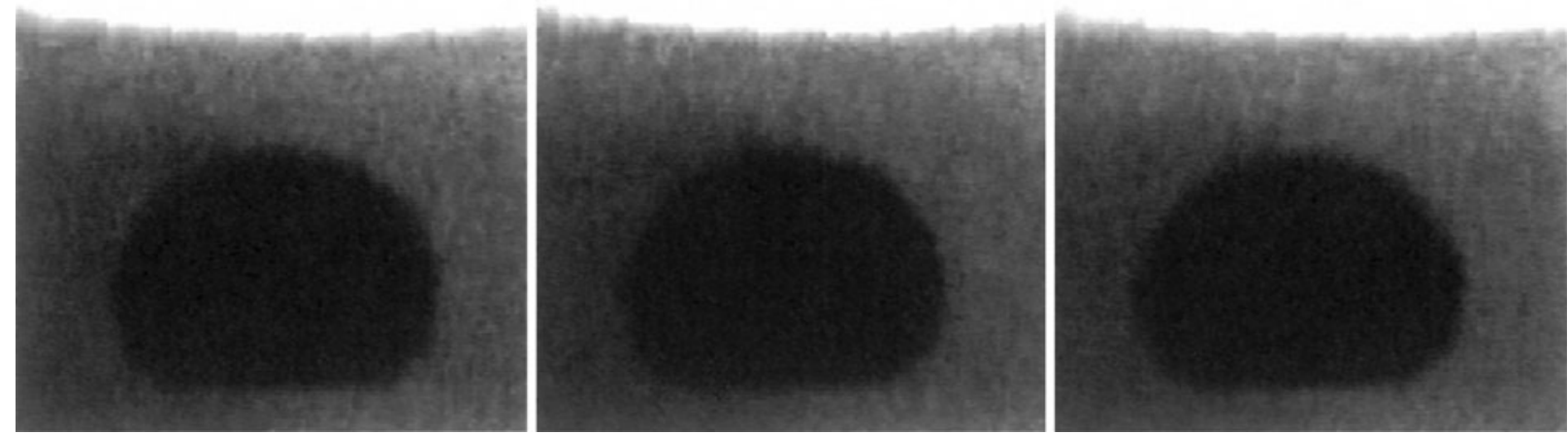

Fig. 6-X-ray images of the iron drop in slag (left to right) at $5 \mathrm{~min}, 17 \mathrm{~min}$, and $32 \mathrm{~min}$ from start of $\mathrm{SO}_{2}$ injection. 
was written to identify the change in height as well as the width of the sessile drop from these picture frames. The change in height/width was later plotted as a function of time. However, the variation in the height/width of the drop was roughly 3-4 pixels. This variation seemed to be too low as it approximated to roughly $0.3 \mathrm{~mm}$ in terms of $5.16 \mathrm{~mm}$ drop height and $9.03 \mathrm{~mm}$ drop width. The variations are comparable with human/manual errors.

The estimation of the interfacial tension from the sessile drop contour under dynamic mass transfer is difficult because of the unstable sessile drop contour, because the stable condition of the drop is obtained from the force equilibrium between the gravitational force and the surface/interface tension force. A change in the interfacial tension could cause a sudden imbalance in the drop shape. The time required for the drop to relax from this unsteady position is more than the frame speed (25 frames/s) at which the individual frames are obtained from the software. For this reason, the contact angle was used as a measure of the change in interfacial tension. From Figure 7, the interfacial tension between the iron drop and the slag phase can be given as a function of the difference between the interfacial tensions of the slag-alumina substrate and the ironalumina substrate.

$$
\sigma_{\mathrm{Fe}-\text { slag }}=\frac{\sigma_{\text {slag-alumina }}-\sigma_{\mathrm{Fe}-\text { alumina }}}{\cos \theta}
$$

It was decided to trace the oscillations with respect to the contact angle variation. It was observed from prior experimental trials that the drop shape stabilized after holding at a constant temperature for 90 minutes. Accordingly, the contact angles (both left and right) for the drop at $1823 \mathrm{~K}\left(1550{ }^{\circ} \mathrm{C}\right)$ held for approximately 110 minutes were taken as the stable configuration. Using the data generated by the height/width variations, three time frames (6 minutes 40 seconds, 17 minutes and 37 minutes from the $\mathrm{Ar}-\mathrm{CO}-\mathrm{SO}_{2}$ gas mixture injection) of roughly 2 seconds duration each were focused on, from which approximately 50 frames each were analyzed. It could be identified that there were two modes of oscillations: one in which the left and right contact angles either both increased or decreased at the same time (which was called symmetric oscillations based on the concept put forward by Jakobsson et $a .^{[16]}$ ) and the other wherein the increase/decrease of the left contact angle resulted in the decrease/increase of the right contact angle (these oscillations were termed as asymmetric oscillations). One reason for the asymmetric oscillations is likely to be the deviation of the

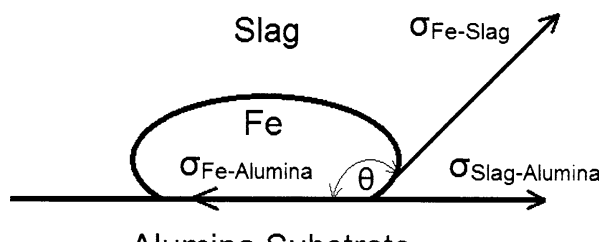

Alumina Substrate

Fig. 7-Forces acting on the sessile drop under equilibrium conditions. position of the sessile drop from the actual center, an extremely slight inclination of the surface or the nonuniform concentration of sulfur at the interface. The variation in the contact angle ranged from 8 to $10 \mathrm{deg}$, which was acceptable for the current evaluations. Oscillations were captured from the time the contact angles of the iron drop matched with that of the stable configuration. This condition was chosen as identification for both the start and end of an oscillation. Figure 8 shows the two modes of oscillations taking place during dynamic mass transfer.

In the 150 frames analyzed, the left and right contact angles of the sessile drop were measured manually. The contact angles of the stable configuration of the sessile drop were obtained from the X-ray image grabbed after holding the metal drop in the slag phase at $1823 \mathrm{~K}$ $\left(1550{ }^{\circ} \mathrm{C}\right)$ for approximately 110 minutes. The deviations of the left and right contact angles of the individual frames from those corresponding to the stable configuration of the drop were plotted as a function of time. The hybrid oscillations taking place between 1016 and 1018 seconds from the introduction of the sulfur source into the slag-metal system is shown in Figure 9. Here, the asymmetric oscillations have been labeled using a star symbol.

The oscillations were assumed to follow a sinusoidal curve and, hence, the total angular displacement caused

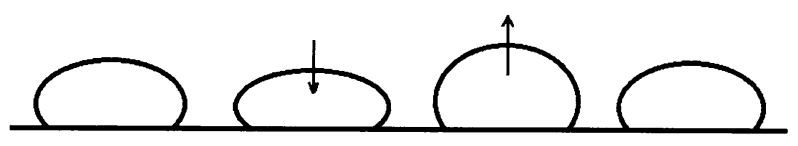

(a)

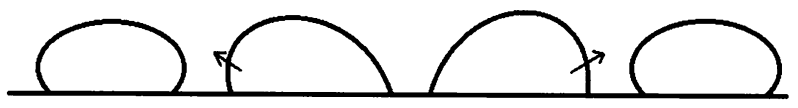

(b)

Fig. 8-Modes of oscillation occurring during mass transfer of sulfur (a) symmetric (b) asymmetric.

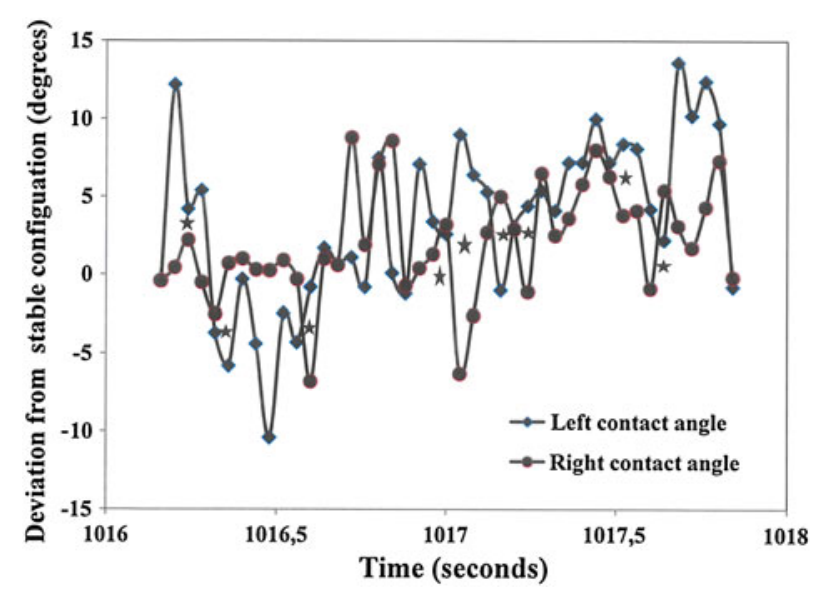

Fig. 9-Hybrid oscillations of the drop measured as a function of the change in the contact angle from the stable configuration of the metal drop. The star symbol represents the asymmetric oscillations. 


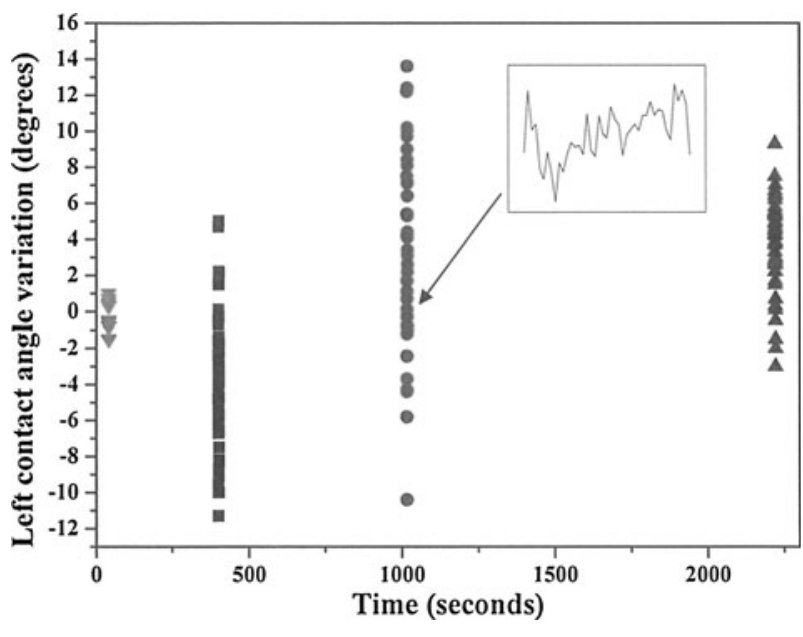

Fig. 10-Variation of left contact angle as a function of time. The time frames 39-41, 399-402, 1016-1018, and 2220-2222 s are too small for the time scale; hence, the contact angle variation appears piled one over the other. Inset in the graph are the oscillations for time frame 1016-1018 s. The deviation of the left contact angles from the equilibrium value for time frame 39-41 s was shown to observe the oscillations occurring because of the sulfur concentration variation at the interface and not because of thermal convection.

by the combination of symmetric and asymmetric parts could be written as

$$
R^{\prime \prime}=A_{1}^{\prime} \times \operatorname{Sin}\left(\omega_{1} \times t\right)+A_{2}^{\prime} \times \operatorname{Sin}\left(\omega_{2} \times t+\Theta\right)
$$

where suffixes 1 and 2 represent the symmetric and asymmetric oscillations, respectively.

An effort was made to distinguish these oscillations mathematically; however, it was difficult to obtain reasonable nonlinear curve fit from the data points.

The angle variation from the stable configuration for both left and right contact angles as a function of time is shown in Figures 10 and 11, respectively. It can be observed that the deviation from the stable profile of the drop increases with time initially but later tends to decrease as it reaches roughly 2222 seconds. The oscillations increase to a maximum amplitude at approximately 1018 seconds. Furthermore, it can also be observed that the deviation from the stable profile tends to be positive as time increases, indicating that sulfur has been absorbed by and accumulated in the drop and the contact angles have consequently increased resulting in a lower interfacial tension. The deviations from the stable configuration at 39-40 seconds were plotted to verify that the oscillation occurred because of the sulfur concentration variation at the interface and because of thermal convection.

After identifying individual oscillations, four frames were taken for each oscillation, which would represent the first expansion (initial condition), depression (dip), and second expansion (rebound). These frames were then processed using a Didge image digitizing software. The software gave the coordinates of the contour of the sessile drop based on a scaling factor. These profile coordinates were used later to get the surface area of the sessile drop from a program written in MATLAB ${ }^{\circledR}{ }^{[29]}$

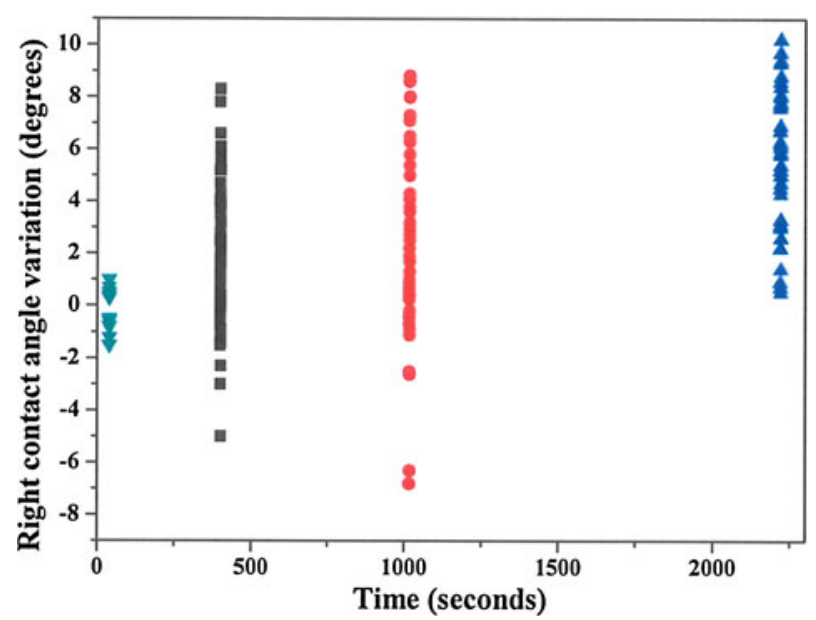

Fig. 11-Variation of the right contact angle as a function of time. The time frames 39-40, 399-402, 1016-1018, and 2220-2222 s are too small for the time scale; hence, the contact angle variation appears piled one over the other. The increase in the deviation from the equilibrium value indicates that the oscillation was a result of sulfur concentration variation along the interface and not because of thermal convection.

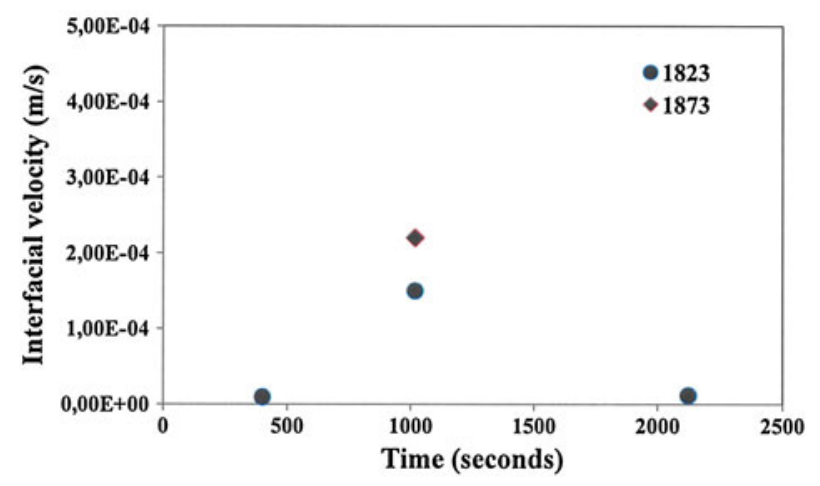

Fig. 12-Interfacial velocity variation as a function of time and temperature.

The program gave the volume and the interfacial area of the drop. From the actual volume of the drop, the actual interfacial area could be computed. As mentioned previously, the change in surface area between frames, and consequently, the interfacial velocity, could be calculated. Figure 12 shows the variation in interfacial velocity as a function of time. The estimated error in measurement was \pm 6 pct.

Similar experiments were conducted also at $1873 \mathrm{~K}$ $\left(1600{ }^{\circ} \mathrm{C}\right)$ to find the effect of temperature on the interfacial velocity. Here, the time frame was chosen corresponding to the maximum oscillation amplitude at $1823 \mathrm{~K}\left(1550{ }^{\circ} \mathrm{C}\right)$. The whole frame processing steps were repeated. A computation of the interfacial velocity at $1873 \mathrm{~K}\left(1600{ }^{\circ} \mathrm{C}\right)$ shows that this velocity increases with temperature increase. The thermophysical and thermochemical properties of the slag used in the calculations were retrieved from Thermoslag software and are shown in Table IV.

As shown in the tables, the activity of $\mathrm{FeO}$ increases with temperature; hence, there is an increase in the 
Table IV. Thermophysical and Thermochemical Properties of the Slag From Thermoslag Software

\begin{tabular}{|c|c|c|c|c|c|c|}
\hline Temperature, $\mathrm{K}\left({ }^{\circ} \mathrm{C}\right)$ & $\mathrm{a}_{\mathrm{FeO}}$ & $\mathrm{a}_{\mathrm{CaO}}$ & $\mathrm{a}_{\mathrm{Al} 2 \mathrm{O} 3}$ & $\mathrm{a}_{\mathrm{SiO} 2}$ & Sulfide Capacity $\left(\mathrm{C}_{\mathrm{s}}\right)$ & Viscosity (poise) \\
\hline $1823(1550)$ & $5.49 \times 10^{-2}$ & $4.85 \times 10^{-4}$ & 0.206 & 0.0283 & $1.1 \times 10^{-4}$ & 6.11 \\
\hline $1873(1600)$ & $5.5 \times 10^{-2}$ & $5.56 \times 10^{-4}$ & 0.213 & 0.0273 & $1.53 \times 10^{-4}$ & 4.29 \\
\hline
\end{tabular}

sulfide capacity of the slag. However, because the viscosity of the slag decreases and the repulsive interaction between the metal and slag increases, the movement of sulfur along the interface is facilitated. From the force balance acting on sulfur at the interface, it could be said that the surface tension difference along the interface is decisive along with the extent of decrease in the viscosity of the slag and metal phases, for estimating interfacial velocity at higher temperatures.

Because the concept of interfacial velocity involves a dilatational term, it could be possible to compute the dilatational viscosity/modulus of the system at the concerned temperatures. An attempt to compute this would be presented as a separate paper because of the size limitations of this manuscript.

\section{CONCLUSIONS}

Dynamic mass transfer of sulfur was studied between pure iron and $\mathrm{CaO}-\mathrm{SiO}_{2}-\mathrm{Al}_{2} \mathrm{O}_{3}-\mathrm{FeO}$ quaternary slag using X-ray studies in a sessile drop furnace. Ar-CO-SO gas mixture was used as the sulfur source to avoid any mixing effects. The metal drop was found to oscillate approximately after 6 minutes of $\mathrm{SO}_{2}$ introduction. The oscillations were studied and it was found to be a hybrid of symmetric as well as asymmetric oscillations. Efforts were made to calculate the change in surface area of the metal drop during the mass transfer to estimate the interfacial velocity. The order of magnitude of the interfacial velocity was found to reach a peak value of the order of $10^{-4} \mathrm{~m} \mathrm{~s}^{-1}$ and had a positive dependence on temperature.

\section{ACKNOWLEDGMENTS}

The authors would like to thank Professor A.K. Lahiri formerly with Indian Institute of Science, Bangalore, India for the fruitful discussions especially on the oscillation modes. The Swedish Research Council (Project No: H 6971) is acknowledged for the financial support.

\section{NOMENCLATURE}

$\sigma \quad$ instantaneous interfacial tension difference from the equilibrium condition $\left(\mathrm{mN} \mathrm{m}^{-1}\right)$

$\mu_{\mathrm{S}} \quad$ interfacial shear viscosity $\left(\mathrm{mN} \mathrm{m}^{-1} \mathrm{~s}(\mathrm{sP})\right)$

$K_{\mathrm{d}} \quad$ interfacial dilatational viscosity $\left(\mathrm{mN} \mathrm{m}^{-1} \mathrm{~s}(\mathrm{sP})\right)$

$v \quad$ surface/interfacial velocity $\left(\mathrm{m} \mathrm{s}^{-1}\right)$

$X \quad$ thickness of the surface/Interface layer (m)

$t \quad$ time (s)

$A_{t} \quad$ instantaneous interfacial area at any time $\mathrm{t}\left(\mathrm{m}^{2}\right)$
$R \quad$ radius of the circle with area equivalent to the interfacial surface area $(\mathrm{m})$

$D_{, \mathrm{S}} \quad$ surface diffusion of sulfur in slag $\left(\mathrm{m}^{2} \mathrm{~s}^{-1}\right)$

$k$ apparent interfacial tension $\left(\mathrm{mN} \mathrm{m}^{-1}\right)$

$T$ temperature $(\mathrm{K})$

$T_{\mathrm{M}} \quad$ melting point of pure iron $(\mathrm{K})$

$W_{\text {ad }}$ The work of adhesion between slag and metal $\left(\mathrm{mN} \mathrm{m}^{-1}\right)$

$\sigma_{\mathrm{m}} \quad$ surface tension of the metal at temperature $T(\mathrm{~K})$

$\sigma_{\mathrm{s}} \quad$ surface tension of the slag at temperature $T(\mathrm{~K})$

$\sigma_{\mathrm{ms}} \quad$ interfacial tension at the slag-metal interface at temperature $T(\mathrm{~K})$

$\phi \quad$ interaction coefficient

$W_{\mathrm{co}}^{\mathrm{m}} \quad$ work of cohesion of the metal phase $\left(\mathrm{mN} \mathrm{m}^{-1}\right)$

$W_{\mathrm{co}}^{\mathrm{s}} \quad$ work of cohesion of the slag phase $\left(\mathrm{mN} \mathrm{m}^{-1}\right)$

$\theta$ contact angle (degrees)

$R^{\prime \prime} \quad$ total angular displacement (radians)

$A^{\prime} \quad$ amplitudes of the oscillations

$\omega \quad$ oscillation frequencies $\left(\mathrm{s}^{-1}\right)$

$\Theta \quad$ phase difference between the symmetric and asymmetric oscillations (degrees)

\section{REFERENCES}

1. G.R. Belton: Metall. Trans. B, 1976, vol. 7B, pp. 35-42.

2. K. Ogino, K. Nogi, and C Hosoi: Tetsu-to-Hagané, 1983, vol. 69 (16), pp. 1989-94.

3. M. Divakar, J.P. Hajra, A. Jakobsson, and S. Seetharaman: Metall. Mater. Trans. B, 2000, vol. 31B, pp. 267-76.

4. E. Kapilashrami, A.K. Lahiri, A.W. Cramb, and S. Seetharaman: Metall. Mater. Trans. B, 2003, vol. 34B, pp. 647-52.

5. B.J. Keene, K.C. Mills, J.W. Bryant, and E.D Hondros: Can. Metall. $Q$, 1982, vol. 21 (4), pp. 393-403.

6. Y. Chung and A.W. Cramb: Metall. Mater. Trans. B, 2000, vol. 31B, pp. 957-71.

7. H. Gaye, L.D. Lucas, M. Olette, and P.V Riboud: Can. Metall. $Q$, 1984, vol. 23 (2), pp. 179-91.

8. A. Jakobsson, M. Nasu, J. Mangwiru, K.C. Mills, and S. Seethraman: Phil. Trans. R. Soc. Lond. A, 1998, vol. 356, pp. 995-1001.

9. P.V. Riboud and L.D Lucas: Can. Metall. Q, 1981, vol. 20 (2), pp. 199-208.

10. I. Jimbo and A.W Cramb: ISIJ Int, 1992, vol. 32 (1), pp. 26-35.

11. S.I. Popel, V.I. Sokolov, and V.G. Korpachev: Fiz. Khimii. Met. Rasplavov, 1959, p. 24.

12. S. Hara, M. Kitamura, and K Ogino: ISIJ Int, 1990, vol. 30 (9), pp. 714-21.

13. Y.A. Minaev and V.A. Grigorian: Zavod. Lab., 1965, vol. 31, p. 809.

14. A.A. Deryabin, S.I. Popel, and L.N. Saburov: Izv. Akad. Nauk SSSR, Metally, 1968, no. 5, p. 51 .

15. K. Ogino, S. Hara, T. Miwa, and S. Kimoto: Trans. ISIJ, 1984, vol. 24 , pp. 522-31

16. A. Jakobsson, N.N. Vishwanathan, S. Du, and S. Seetharaman: Metall. Mater. Trans. B, 2000, vol. 31B, pp. 973-80.

17. F.D. Richardson: Physical Chemistry of Melts in Metallurgy vol. 2, Academic Press, New York, NY, 1974.

18. L. Muhmood, N.N. Viswanathan, and S. Seetharaman: Metall. Mater. Trans. B. in press.

19. F. Bashforth and J.C. Adams: An Attempt to Test the Theories of Capillarity, Cambridge University Press, Cambridge, UK, 1883. 
20. A.W. Adamson: Physical Chemistry of Surfaces, 3rd ed., Wiley, New York, NY, 1976, p. 118

21. F. van Voorst Vader, T.F. Erkens, and M. van denTemple: Trans. Faraday Soc., 1964, vol. 60, pp. 1170.

22. J.A. Bustnes: Metall. Mater. Trans. B, 1997, vol. 28B, pp. 613-18.

23. Thermocalc: Royal Institute of Technology, Stockholm, Sweden. http://www.thermocalc.com/.

24. K. Schwerdtfeger and E.T. Turkdogan: Equlibria and Transport Phenomena Involving Gas Mixtures and Condensed Phases, vol. 4, R.F. Bunshah, ed., Interscience Publishers, New York, NY, 1970, p. 321.

25. L. Muhmood, N.N. Viswanathan, M. Iwase, and S. Seetharaman: Metall. Mater. Trans. B. DOI: 10.1007/s11663-011-9492-7.

26. T. Saitô and Y. Kawai: J. Jpn. Inst. Met., 1953, vol. 17, p. 434.

27. Y. Kawai: Science Reports of the Research Institutes, Tohoku University, Japan, 1957, Ser. A, pp. 78-83.

28. Thermoslag: Division of Materials Process Science, Royal Institute of Technology, Stockholm, Sweden, 1996.
29. MATLAB: Mathworks, ver. R2009b, 2009. http://www.mathworks. $\mathrm{com} /$.

30. I. Egry, G. Lohöfer, and S. Sauerland: J. Non-Cryst. Solids, 1993 , vols. $156-158$, pp. 830-32.

31. R. Sangiorgi, M.L Muolo, and A. Passerone: Acta. Metall., 1982, vol. 30 , pp. $1597-604$

32. A. Kasama, T. Iida, and Z. Morita: J. Jpn. Inst. Met., 1976, vol. 40, pp. 1030-38.

33. L. Muhmood and S. Seetharaman: Metall. Mater. Trans. B, 2010, vol. 41B, pp. 833-40.

34. M. Persson, J. Zhang, and S Seetharaman: Steel Res. Int, 2007, vol. 78 (4), pp. 290-98.

35. J.E. McDonald and J.G. Eberhart: Trans. TMS-AIME, 1965, vol. 233 , pp. $512-17$.

36. L.A Girifalco and R.J. Good: J. Chem. Phys., 1957, vol. 61, pp. 904-09.

37. D.J. Steinberg: Metall. Trans., 1974, vol. 5, pp. 1341-43. 